\title{
ЭКОНОМИКА УСЫНОВЛЕНИЯ КАК СТРАТЕГИЯ ВЫЖИВАНИЯ МАЛЫХ СЕЛ (НА ПРИМЕРЕ БУРЯТИИ)
}

\begin{abstract}
В статье проанализированы практики экономики усыновления, которые способствуют выживанию малых сел в условиях тотального сокращения государственного финансирования образования. Под экономикой усыновления понимается совокупность социально-экономических отношений, которые складываются вокруг практик усыновления, опеки, попечительства и приемной семьи. Показано, как, с одной стороны, политика в сфере образования, нацеленная на закрытие школ с убывающим числом учеников, и, с другой стороны, политика в сфере социального обеспечения, активно стимулирующая увеличение числа приемных семей, создают условия для формирования особых практик экономики усыновления в малых селах. Жители малых сел, в которых школы находятся на грани закрытия, выбирают тактику увеличения числа учеников школы с помощью приемных детей. Статья основана на материалах полевого исследования, проведенного в республике Бурятия в рамках стратегии множественного кейс-стади (2018). Исследование позволило выявить случаи, когда в поселениях с похожей социально-экономической структурой и этническим составом, экономика усыновления привела к разным эффектам. В одних поселениях она позволила сохранить школы, а в других - школы были закрыты. Авторы обращаются к теории социального капитала Коулмана, чтобы понять, почему экономика усыновления эффективна в одних поселениях и неэффективна в других. Анализ материалов показывает, что в целом приемные семьи демонстрируют высокий социальный капитал, который выражается в формировании тесных отношений на основе множества непогашенных обязательств между приемными детьми и родителями. Решающим фактором успешности экономики усыновления в сохранении
\end{abstract}

Вера Валериевна Галиндабаева - к.с.н., ст.н.с., Социологический институт РАН- филиал ФНИСЦ РАН, Санкт-Петербург, Россия. Электронная почта: vgalindabaeva@gmail.com

Николай Иванович Карбаинов- н.с., Социологический институт РАН- филиал ФНИСЦ РАН, Санкт-Петербург, Россия. Электронная почта: nkarbainov@gmail.com 
школ стал высокий социальный капитал сельских сообществ. Там, где социальный капитал был низким, школы закрыли, и это привело к сокращению населения в этих селах. Основными индикаторами высокого капитала сельского сообщества мы выделили наличие в селе: приемных родителей, которые не работают в школе, ТОСы, которые успешно благоустраивают территорию села, и наличие локального религиозного календаря событий, в праздновании которых принимают участие все жители.

Ключевые слова: экономика усыновления, приемные семьи, социальный капитал, малокомплектные школы, Бурятия

DOI: 10.17323/727-0634-2020-18-2-207-220

В этой статье описываются практики экономики усыновления, которые способствуют выживанию малых сел в условиях сокращения государственного финансирования образования. Под экономикой усыновления мы понимаем совокупность социально-экономических отношений, которые складываются вокруг практик усыновления, опеки, попечительства и приемной семьи. Таким образом, в нашем исследовании мы используем понятие «усыновление» не в узком юридическом понимании, как одной из форм семейного устройства, а в более широком смысле как социальную практику опеки неродного ребенка.

В 2000-е гг. в разных регионах России жители малых сел начинают массово брать детей под опеку, чтобы увеличить количество учеников в школе и снизить вероятность ее закрытия в селе (Гнединская 2009). В выборку исследования вошли кейсы малых сел, которые, судя по материалам СМИ, успешно использовали экономику усыновления для сохранения школы (Галлас 2007). Однако в ходе полевого исследования, проведенного в Бурятии, выявлены случаи, когда стратегия усыновления не привела к сохранению школ.

В статье мы отвечаем на вопрос, почему в селах с похожей социальноэкономической и этнической структурой, экономика усыновления давала разные результаты. Для этого сначала опишем контекст возникновения экономики усыновления в исследованных малых селах России и, в том числе Бурятии, т.е. контекст и эмпирическую базу исследования. Далее мы обратимся к теории социального капитала и анализу эмпирических кейсов.

\section{Контекст возникновения экономики усыновления в малых селах Бурятии}

С началом постсоветских экономических реформ и кризиса сельского хозяйства не прекращается падение числа занятых в сельскохозяйственном производстве в климатически благоприятных и неблагоприятных для сельского хозяйства районах России (Нефедова 2007). Альтернативная занятость 
или неформальные экономические практики позволяют сельчанам выжить в условиях тотального сокращения рынка труда (Серова, Звягинцев 2006; Барсукова, Радаев 2012). В сфере здравоохранения и образования, по данным исследователей, в России занято более трети сельских женщин в трудоспособном возрасте (Серова и др. 2006). Кроме того, работа в бюджетной сфере самая желанная для сельских жителей, поскольку дает стабильную занятость и оплату труда без сезонных колебаний, которым подвержен сельскохозяйственный труд (Аверкиева, Землянский 2016). Таким образом, рабочие места (в среднем 20-30 мест), которые предоставляет школа, являются значимым источником дохода для населения сел, особенно для женщин.

Однако государство с середины 2000-х гг. последовательно сокращает расходы на содержание школ, вводя нормативно-подушевое финансирование. По замыслу реформаторов нормативное подушевое финансирование создаст конкурентную среду для школ, заставив их повышать качество образования в борьбе за привлечение большего количества учеников (Абанкина и др. 2016). На деле все больше школ закрывается, в особенности в сельской местности, где конкурировать за учеников не приходится. Половина сельских школ по новым нормативам являются малокомплектными. Закрытие малокомплектных школ позволяет эффективно расходовать бюджетные средства, а именно сократить расходы на содержание имущества. Однако закрытие школы- фатальное для малого села событие. Дело здесь не только в том, что часть населения лишается работы (в сфере образования), а в том, что молодые семьи даже при наличии работы начинают выезжать в более крупные села и города, где доступно образование для их детей.

Политика оптимизации школьной системы совпала по времени с трендом на деинституциализацию государственной сферы заботы о детях, оставшихся без попечения родителей, и сокращения числа интернатов (Шпаковская и др. 2019: 58). Приоритет семейных форм устройства детей, оставшихся без попечения родителей, прописан в Семейном кодексе РФ, но только после 2006 г. разработаны и введены механизмы по уменьшению числа детей в институциальных учреждениях. С 2008 г., когда был принят новый закон, приемная семья стала самой развивающейся формой семейного устройства детей. Процент детей, помещенных в приемные семьи, с 2005 по 2015 гг. возрос с 2\% до $24 \%$ от числа детей, оставшихся без попечения родителей (Biryukova, Sinyavinskaya 2017).

Рассмотрим, как реализовывались реформы в образовании и системе государственной защиты детей, оставшихся без попечения родителей, в Бурятии. В 2007 г. республика включилась в Комплексный проект модернизации образования в части перехода на новую систему оплаты труда учителей, основанную на нормативно-подушевом принципе. Расходы на обучение в сельских школах в расчете на одного учащегося в среднем в 2,5-4 раза выше аналогичных расходов в городских школах. Рассчитывалось, что реструктуризация сети сельских школ позволит сократить 
до 10-12\% бюджетных расходов в течение 3-5 лет (Постановление правительства... 2006).

Малокомплектными школами в республике признавали общеобразовательные учреждения, в которых наполняемость классов менее десяти человек (Закон Республики Бурятия 2007). В 2013 г. принят новый закон об образовании, в соответствии с которым данный статус школы получают при следующих условиях: начальные школы при количестве учеников не более 40 человек; основные школы (9 классов) - не более 90 человек; средние школы- не более 110 человек (Закон Республики Бурятия 2013). При снижении числа учеников до 40 чел. в основных школах и до 50 чел. в средних целевая программа оптимизации рекомендует переводить детей на обучение в более крупную соседнюю школу при условии организации подвоза. В 2006 учебном году от общего количества 564 школ: сельских 425 (78\%), малокомплектных - 221 (39\%) (Постановление правительства... 2006). В 2010 г. сельские школы составляли 77,7\% от общего количества школ в республике, из них 49,6\% - сельские малокомплектные. За период с 2000 по 2010 гг. количество учащихся сельских общеобразовательных школ в республике сократилось на 69,5 тысяч человек, а число школ- на 91. Средняя наполняемость в классах сельских школ республики составляла 14 условных учащихся (Дамдинов 2011). В период с 2008 по 2017 гг. закрыто 48 сельских малокомплетных школ, в том числе десять филиалов.

В 2007 г. одновременно с реализацией проекта образования правительство республики разрабатывает и принимает целевую программу «Семья и дети Республики Бурятия на 2008-2014 годы» (Постановление правительства... 2007). Одной из главных задач программы было увеличение доли детей, находящихся в приемных семьях до 18,7\% (или 1190 человек). Подобные целевые документы принимались и до 2007 г., но строгих показателей прописано не было. Первые приемные семьи появились в республике в 2002 г., их количество увеличивалось постепенно с 25 до 409 семей, а число приемных детей - с 40 до 632 в 2009 г. (Байкал 24 2010). К 2015 г. уже 1451 ребенок находится в 853-х приемных семьях (Центр социальной поддержки населения 2019).

В собранных нами интервью специалист органов опеки Хоринского района Бурятии также подтверждает наличие взаимосвязи между введением подушевого финансирования в образовании и резкого увеличения приемных семей:

Вообще, у нас изначально в Хоринском районе, вот я сегодня смотрела примерно перед вами статистику свою, где-то в 2008 году у нас было всего несколько, там 7-8 приемных семей. Когда малые села, пошла реформа образования, что надо закрывать малокомплектные школы, у нас учителя пошли на то, чтобы сохранить село, сохранить школу. Потому что мы знаем, что если школы нет, то села и нет. Особенно в малых селах. < ..> И в 2011 году у нас было самое большое количествоэто 45 приемных семей, где воспитывалось 75 детей (Интервью № 43). 
Таким образом, с одной стороны, политика в сфере образования нацелена на закрытие школ с убывающим числом учеников, с другой стороны, политика в сфере социального обеспечения активно стимулирует увеличение числа приемных семей и количества детей в них. В сложившихся условиях жители малых сел, в которых школы находятся на грани закрытия, выбирают тактику увеличения числа учеников школы с помощью приемных детей.

\section{Эмпирическая база}

Масштабы распространения данной практики в малых селах неизвестны, поэтому исследование проводилось в рамках стратегии множественного кейсстади (Yin 2004), которую мы рассматриваем как эмпирическое исследование, нацеленное на глубинное познание социального феномена, включающее изучение контекстуальных условий его формирования и функционирования. Кейсы для исследования отобраны на основании собственных полевых данных и материалов СМИ: улусы Элысун, Тохорюкта, Барун-Хасурта и Кульский станок. Летом 2018 г. проведена экспедиция в Бурятию. Всего проведено 45 интервью с приемными детьми, приемными родителями, главами и заместителями глав поселений, директорами школ, руководителями районных и региональных управлений образованием, специалистами районных и региональных органов опеки и попечительства, директором детского дома. Помимо интервью участники проекта вели дневник наблюдения на протяжении экспедиции и собирали документы по теме исследования.

Все поселения, которые вошли в выборку исследования, обладают похожей социально-экономической и этнической структурой. Подавляющее большинство населения- буряты, исповедующие буддизм и/или шаманизм. Подавляющее число приемных детей воспринимаются как русские (в интервью со специалистами области образования, органов опеки и попечительства, приемными родителями, большинство из которых стремились усыновить бурятских детей, но в итоге были «вынуждены» взять в свои семьи детей русского происхождения). Почти все приемные семьи на момент появления приемных детей переживали фазу «пустого гнезда»: у всех взрослые дети, которые уже проживали отдельно, и у кого-то даже внуки. Опыта приемных семей до 2008 г. в этих селах не было.

Все жители ведут свои подсобные хозяйства, разводят мелкий и крупный рогатый скот для личного потребления и продажи. Есть вахтовики, которые ездят на вахту или «калымы». Осенью сбор дикоросов приносит доход жителям всех сел. В каждом поселении работает сельский дом культуры, библиотека, фельдшерско-акушерский пункт, сельская администрация, отделение почты, один или два магазина и крестьянско-фермерские хозяйства. На момент принятия решения о создании приемных семей во всех селах работали детские сады, школы и сельскохозяйственные производственные кооперативы (СПК), наследовавшие колхозы. 
Несмотря на то что эти поселения имеют схожие социально-экономические характеристики и этническую структуру, экономика усыновления позволила сохранить школы только в Элысуне и Тохорюкте, а в Кульском Станке и Барун-Хасурте школы были закрыты, что в конечном итоге привело к резкому сокращению населения в этих поселениях.

\section{Теория Джеймса Коулмана}

Мы обращаемся к теории социального капитала, чтобы ответить на вопрос, почему в селах с похожей социально-экономической и этнической структурой экономика усыновления давала разные эффекты. В интерпретации Джона Коулмана, социальный капитал является свойством структуры социальных связей между акторами. Главная функция социального капитала- в обеспечении актора ресурсами, с помощью которых он может достигать поставленные цели (Коулман 2001). Автор выделяет три формы социального капитала: обязательства и ожидания, информационные каналы и социальные нормы.

В некоторых социальных структурах существует множество непогашенных обязательств акторов по отношению друг к другу, члены таких сообществ всегда что-то делают друг для друга. Членам сообществ с высоким уровнем обязательств доступно намного больше социального капитала, на который они могут положиться (там же). Важная форма социального капитала- возможность получения информации. Социальные отношения облегчают актору доступ к информации. Нормы и эффективные санкции являются другой формой социального капитала. Предписываемая норма поведения в коллективе, которая является особенно важной формой социального капитала- это норма, побуждающая каждого жертвовать своими интересами и действовать в интересах коллектива. Замкнутость социальной организации повышает эффективность норм, расширяет обязательства и ожидания внутри сообщества (там же).

Основываясь на теории Коулмана, можно предположить, что высокий социальный капитал приемной семьи и сельского сообщества обуславливает успешность стратегии усыновления. Мы выделяем следующие индикаторы высокого социального капитала семьи и сообщества. Во-первых, индикаторами высокого социального капитала семьи можно назвать интенсивное взаимодействие приемных детей с родителями, с детьми приемных родителей, с широким кругом родственником. Важно отметить и то, что дети и родители почти не обращаются в органы с просьбой о расторжении договора. Во-вторых, мы выделяем следующие показатели высокого социального капитала сообщества: среди приемных родителей большое число тех, кто не работает в школе и напрямую материально не заинтересован в сохранении школы; в селе действуют горизонтальные или аппроприативные организации. 


\section{Социальный капитал приемной семьи}

Приемные семьи во всех поселениях демонстрируют высокий социальный капитал, который выражается в формировании тесных отношений на основе множества непогашенных обязательств между приемными детьми и родителями. Особенно хорошо это демонстрирует ситуация, которая складывается в семье после окончания договора. Формально закрепленные договором обязательства приемных родителей перед приемными детьми завершаются с наступлением совершеннолетия. Дальше уже приемный ребенок находится на государственном обеспечении в ссузе или вузе, после окончания которого он должен получить жилье и жить самостоятельно. На деле приемные родители не могут отказаться от выполнения обязательств перед детьми после завершения договора:

Хотя 18 лет исполнилось, контракт кончился. Он к нам как к себе домой приходит, мы его принимаем. Не можем же мы- извини, контракт кончился, иди отсюда. И вот Сергей Владимирович от и до за ними [за своими приемными детьми] смотрит. Вот Ирина [Ирине было 24 года на тот момент] родила внучку. В ночь выехали, детские пеленки, все приданое, купили продукты, все прочее (Интервью № 14).

На момент интервью приемный сын уже вернулся из армии и поехал с приемным отцом на лето на заработки. В Тохорюкте нам рассказали, как, например, приемная мать два года добивалась оформления пенсии по потере кормильца для ребенка. Пенсия по потере кормильца начисляется на карту ребенка, и приемный родитель почти не имеет к ней доступа.

Информационные потоки также являются формой социального капитала, которая облегчает определенные действия для акторов. В улусах, где большинство населения буряты, национальный язык является основным в семейном общении. Никто из приемных детей не владел бурятским на момент начала проживания в приемной семье. Через год-два почти все дети стали понимать, а кто-то даже говорить. С освоением бурятского языка дети получают доступ к информации, которая была им недоступна из-за языкового барьера:

Я раньше думала, что они не понимают. Если двое детей, они в интернете постоянно, я думала, они не понимают. Один раз что-то про них сказала я- одежду не привезли, где одежда половина? Какие дети?-так по-бурятски. Мама, говорит, ты, что говоришь так? Мы же все понимаем! (Интервью № 40).

Знание бурятского языка дает приемным детям особое признание со стороны односельчан и жителей района. Между старшими детьми приемных родителей и приемными детьми также выстраиваются тесные отношения. Многие дети живут в Улан-Удэ и помогают приемным детям. Приемные дети втягиваются в отношения не только внутри нуклеарной 
семьи, но в отношения с широким кругом родственников. Отношения с родственниками подкрепляются не только совместным времяпровождением, но и реципрокными обменами. Приемная мать описывает, как родственники провожали ее приемного сына в другой город поступать в военное училище: «Недавно проводины делали, он в <..> поехал, человек 60-70 собралось, в основном все свои. На дорожку ему денег давали, хорошие слова говорили〉 (Интервью № 23).

Почти все дети приобщились к буддизму и/или шаманизму за время проживания в бурятских семьях. В интернатах дети, считающиеся русскими, проходят обряд крещения и приходят в семью уже с православными атрибутами - крестиком и свидетельством о крещении. Однако кроме крещения дети не участвовали в других православных обрядах. Обращение к буддизму способствует укреплению отношений с приемными родителями. Более того многим приемным родителям ламы и шаманы советуют приобщать приемных детей к религии, так как эти дети по факту становятся частью семьи и рода:

O: Мы съездили в дацан, говорю- сына взяли. Веру поменять. Поменяли. Сказали - это ваш сын уже, бурят.

B: То есть, именно не к шаману, а в дацан ходили?

O: В дацан ходили. Потом к шаману ходила после, как взяли. И веру ему поменяли.

В: То есть, он уже буддист, правильно?

О: Буддист.

В: И шаманист тоже, да?

О: Да. Сказали, обязательно надо поменять веру (Интервью № 12).

Некоторым детям давали в дацане бурятские имена, которыми они пользуются в основном при проведении обрядов.

Во всех селах были случаи расторжения договоров со стороны приемных родителей. Основными причинами наши информанты и специалисты органов опеки называли проблемы со здоровьем у приемных родителей, у приемных детей, проблемы взаимопонимания между родителями и детьми в период подросткового кризиса.

\section{Социальный капитал сообщества}

Социальный капитал сельских сообществ должен быть достаточно высок, чтобы его члены решились на усыновление такого количества детей для общего блага, спасения школы. Коулман подчеркивает, что коллективные действия ради общего блага требуют от акторов больше ресурсов, чем они в итоге могут получить обратно. Школа является таким 
общим благом для сельского сообщества. Все жители села получают выгоду, хотя вкладывают ресурсы ограниченная часть жителей.

В Элысуне и Тохорюкте главы поселений наравне с директорами школ принимали активное участие в убеждении жителей села в необходимости приемных детей. Среди приемных родителей были как работники школы, так и те жители, которые не были трудоустроены в школе. В Кульском станке основную инициативу выдвинул директор школы, и приемные семьи в основном создавались учителями и работниками школы. Заинтересованность учителей в приемных детях была везде одинаково высока и связана в первую очередь с желанием сохранить рабочие места и доходы от профессиональной деятельности. У жителей, не работающих в школе, намного меньше материальных мотивов для обращения к усыновлению. При этом семьи, которые соответствуют требованиям, предъявляемым к приемным семьям, зачастую являются обеспеченными. Денежные суммы, выделяемые на содержание ребенка и на оплату труда только одного приемного родителя, не являются для них основным мотивом. Опыт приемного родительства оценивается как акт благодеяния в отношении детей и сельского сообщества. Таким образом, жители первых двух поселений изначально были более склонны жертвовать своими интересами для сохранения общего блага, чем жители двух других улусов.

Интенсивные взаимоотношения между односельчанами, поддерживаемые разными видами совместной деятельности, мы рассматриваем как основной показатель высокого социального капитала сельского сообщества. Важной формой совместной деятельности в малых селах сегодня являются территориальные общественные самоуправления (ТОС). Они не входят в структуру органов местного самоуправления, а представляют собой отдельную форму самоорганизации граждан по месту их жительства и регистрируются как некоммерческие организации. В малых селах ТОСы объединяют всех жителей поселения и становятся новой ареной приложения коллективных усилий. ТОСы, в перспективе теории Коулмана, представляют собой аппроприативные организации, которые используют сложные отношения, то есть участники связаны не только местом проживания, но и местом работы, родственными отношениями (Коулман 2001).

В первых двух поселениях действуют ТОСы, которые ежегодно выигрывают деньги для осуществления мероприятий по обустройству своих территорий. Глава Ойбонтовского поселения, в которое входит Тохорюкта, рассказал о ТОСах так:

Было организовано 2 ТОСа, <..> На 70-летие победы была сделана огромная реконструкция памятника павшим землякам Великой отечественной войны. В принципе, там мы ТОС-овских денег вложили 40 тысяч всего. На самом деле весь этот проект обошелся нам порядка 250 тысяч. Остальные деньги, откуда взяли? Это собственные средства. Школа и администрация совместно провели марафон, начали искать 
потомков, родственников. <..> За работу, конечно, мы ни копейки никому не платили (Интервью № 34).

В этих же поселениях есть свой локальный религиозный календарь. В Элысуне жители считают, что они живут в священном треугольнике, углы которого образуются тремя святыми местами. Тохорюкта находится в центре буддистской мельницы (хурдэ), а вокруг расположены четыре святыни. Ежегодно в соответствии с календарем на каждом месте проводятся молебны и национальные игры, в которых принимают участие все жители поселений.

В отличие от первых двух поселений в Кульском станке и Барун-Хасурте нет ТОСов и своих локальных календарей религиозных событий. Социальный капитал сообщества недостаточно высок в этих поселениях, чтобы жители смогли объединиться для благоустройства территории села или для создания локального календаря событий. Это мы можем увидеть и в том, как происходило закрытие школ в этих двух поселениях.

Рассмотрим закрытие школы в Кульском станке, и как население отреагировало на это решение. Решение о ликвидации школы принимает учредитель, то есть районные власти. По закону учредитель должен учитывать мнение жителей поселения, поэтому сначала проводится сельский сход, на котором представители администрации объявляют о своем решении. В Кульском станке на момент закрытия школа уже была начальной, и в ней обучалось 19 человек. Специалист районного управления образованием Хоринского района так описала закрытие школы:

Видите, почему закрыли, потому что сами родители пошли жаловаться на школу, что качество обучения плохое. А потом, когда начали уже детей привозить сюда [в районный центр] и понятно стало, что дети пол дня бывают здесь, когда еще автобус их привезет? Затем они пришли сюда жаловаться открыть. А открыть уже очень трудно (Интервью № 39).

Таким образом, высокий социальный капитал сельских сообществ в Элысуне и Тохорюкте стал решающим фактором сохранения школ в этих поселениях. В Кульском Станке и Барун-Хасурте, несмотря на высокий социальный капитал семей, школы сохранить не удалось из-за низкого социального капитала сообществ.

\section{Заключение}

Мы описали как жители малых сел, в которых школы находятся на грани закрытия, выбирают тактику увеличения числа учеников школы с помощью приемных детей. Однако описанная тактика давала разные результаты в селах с похожей социально-экономической и этнической структурой. Мы обратились к теории социального капитала Коулмана, чтобы понять насколько высокий социальный капитал приемной семьи 
и сельского сообщества обуславливает успешность стратегии усыновления в сохранении школы и села.

Социальный капитал приемных семей оказался одинаково высоким во всех селах. Существенные различия наблюдаются в социальном капитале сельских сообществ в изучаемых поселениях. Главными индикаторами высокого капитала сообщества мы выделили наличие в селе: приемных родителей, которые не работают в школе, ТОСов, которые успешно благоустраивают территорию села, и локального религиозного календаря событий, в праздновании которых участвуют все жители. Высокий социальный капитал всех членов сельского сообщества становится решающим условием успешности коллективной стратегии по сохранению села и школы.

\section{Выражение признательности}

Исследование проводилось в рамках проекта «Экономика усыновления как стратегия выживания малых сел», финансируемого Фондом поддержки социальных исследований «Хамовники».

\section{Список источников}

Абанкина И. В., Алашкевич М.Ю., Винарик В. А., Деркачев П. В., Меркулов М.В., Славин С. С., Филатова Л. М. (2016) Анализ нормативного подушевого финансирования общего образования в субъектах Российской Федеращии. М.: НИУ ВШЭ.

Аверкиева К.В., Землянский Д. Ю. (2016) Структура занятости сельского населения в Центральном Черноземье. Вестник Московского университета. Сер. 5. География, 2: $75-81$.

Барсукова С. Ю., Радаев В.В. (2012) Неформальная экономика в России: краткий обзор. Экономическая соииология, 13 (2):99-111.

Галлас А. (2007) В деревнях, чтобы сохранить школы, усыновляют детей. Байкал инфо. Доступно по ссылке: http://baikal-info.ru/numberl/2007/07/005001.html (дата обращения: 8 июля 2019).

Гнединская А. (2009) Сельские учителя спасли школу и приютских детей. Московский комсомолеи. Доступно по ссылке: http:/www.mk.ru/editions/daily/article/2009/08/31/343121almamater.html (дата обращения: 8 июля 2019).

Дамдинов А. В. (2011) Актуальные проблемы развития сельских школ Республики Бурятия. Вестник Бурятского государственного университета. Педагогика. Филология. Философия, (1):32-35.

Закон Республики Бурятия (2007) О внесении изменений в закон Республики Бурятия «Об образовании» № 51-IV от 27.12.2007 г.

Закон Республики Бурятия (2013) Об образовании в Республике Бурятия N 240-V от 13.12.2013 г. 
Байкал 24 (2010) В 15 раз увеличилось количество приемных детей в Бурятии. Доступно по ссылке: https://baikal24.ru/text/24-02-2010/uvelichilos/ (дата обращения: 8 июля 2019)

Коулман Дж. (2001) Капитал социальный и человеческий. Общественные науки и современность, (3): 121-139.

МО СП Хоринское (2016) Население. Доступно по ссылке: http://www.sphor.ru/onas/ naselenie (дата обращения: 8 июля 2019)

Нефедова Т. Г. (2007) Местность, где кадры решают все. Отечественные записки, 3 (36): 214-229.

Постановление правительства Республики Бурятия (2006) Об утверждении ресnyбликанской целевой программы «Оптимизация сети сельских общеобразовательных учреждений в Республике Бурятия» на 2006-2008 годы № 65 от 06.03.2006 г.

Постановление правительства Республики Бурятия (2007) Об утверждении ресnубликанской целевой программы «Семья и дети Республики Бурятия на 2008-2014 годbl» № 156 от 08.09.2007 г.

Серова Е. В., Звягинцев Д. В. (2006) Альтернативная занятость в сельской местности. Мир России, (4): 3-34

Серова Е., Карпова Н., Тихонова Т., Шик О., Мокшина П. (2006) Альтернативная занятость в сельской местности России. М: Институт экономики переходного периода.

Центр социальной поддержки населения (2019) Социальный паспорт населения Республики Бурятия на 1 июня 2019 года. Доступно по ссылке: www.cspn-rb.ru/rehab/ stat/passport/ (дата обращения: 8 июля 2019).

Шпаковская Л., Кулмала М., Чернова Ж. (2019) Идеальная организация заботы о детях, оставшихся без попечения родителей: реформы системы защиты детей как борьба за ресурсы и признание. Laboratorium, 11 (1): 57-81.

Biryukova S., Sinyavinskaya O. (2017) Children out of Parental Care in Russia: What We Can Learn from the Statistics. The Journal of Social Policy Studies, 15 (3):367-382.

Yin R. K. (2004) The Case-study Anthology. London: Sage. 
Vera Galindabaeva, Nikolay Karbainov

\section{THE ECONOMICS OF CHILD ADOPTION AS A SURVIVAL STRATEGY FOR SMALL VILLAGES. THE CASE OF BURYATIA}

This article examines practices in the economy of adoption, which contribute to the survival of small villages in conditions where state financing of education is being reduced. The economics of adoption is understood as a set of social and economic relations that develop around the practices of adoption, guardianship and fostering. We demonstrate the influence of two policies on the formation of special economic practices of adoption in small villages: (1) educational policy aimed at closing schools with a decreasing number of pupils; (2) social security policy that actively encourages an increase in the number of foster families. Data collection was conducted in the summer of 2018 in the Republic of Buryatia as part of a wider strategy of multiple case studies. The study revealed cases when, in villages with a similar socio-economic structure and ethnic composition, the adoption economy had different effects. The authors turn to Coleman's social capital theory in order to understand why adoption economics was effective in some settlements, and not in others. An analysis of the empirical materials shows that, in general, families in all settlements demonstrate high social capital, which is expressed in the formation of close relations based on the many outstanding obligations between adopted children and parents. The solidarity of the village dwellers became the decisive factor in the preservation of the underfilled schools and the reproduction of the adoption economy.

Key words: adoption economy, adoptive families, social capital, underfilled schools, Buryatia

DOI: 10.17323/727-0634-2020-18-2-207-220

\section{References}

Abankina I. V., Alashkevich M. Yu., Vinarik V.A., Derkachev P. V., Merkulov M. V., Slavin S. S., Filatova L. M. (2016) Analiz normativnogo podushevogo finansirovaniya obshchego obrazovaniya v sub"ektakh Rossiyskoy Federatsii [Analysis of Normative per Capita Financing of General Education in the Constituent Entities of the Russian Federation]. Moscow: HSE Press.

Averkieva K. V., Zemlyanskiy D. Yu. (2016) Struktura zanyatosti sel'skogo naseleniya v Tsentral'nom Chernozem'e [Employment Structure of Rural Population in the Central Black Earth Region]. Vestnik Moskovskogo universiteta. Ser. 5. Geografiya [Bulletin of Moscow University. Ser. 5. Geography], (2): 75-81.

Vera V. Galindabaeva - PhD (Kandidat Nauk) in Sociology, Senior Research Fellow, Sociological Institute of RAS - Branch of the Federal Center of Theoretical and Applied Sociology of the Russian Academy of Sciences, St. Petersburg, Russian Federation. Email: vgalindabaeva@gmail.com

Nikolay I. Karbainov - Research Fellow, Sociological Institute of RAS - Branch of the Federal Center of Theoretical and Applied Sociology of the Russian Academy of Sciences, St. Petersburg, Russian Federation. Email: nkarbainov@gmail.com 
Bajkal 24 (2010) V 15 raz uvelichilos' kolichestvo priemnyh detej v Buryatii [The Number of Adopted Children in Buryatia Increased by Fifteen Times]. Available at: https://baikal24.ru/ text/24-02-2010/uvelichilos/ (accessed 8 July 2019).

Barsukova S.YU., Radaev V.V. (2012) Neformal'naya ekonomika v Rossii: kratkij obzor. [The Informal Economy in Russia: A Brief Overview]. Ekonomicheskaya sociologiya [Economic Sociology], 13 (2): 99-111.

Biryukova Sv., Sinyavinskaya O. (2017) Children out of Parental Care in Russia: What We Can Learn from the Statistics. The Journal of Social Policy Studies, 15 (3):367-382.

Coleman J. (2001) Kapital social'nyj i chelovecheskij [Social Capital and Human Capital]. Obshchestvennye nauki i sovremennost' [Social Sciences and Modernity], (3): 121-139.

Damdinov A. V. (2011) Aktual'nye problemy razvitiya sel'skih shkol Respubliki Buryatiya [Urgent Problems of Rural Schools Development in the Republic of Buryatia]. Vestnik Buryatskogo gosudarstvennogo universiteta. Pedagogika. Filologiya. Filosofiya [Bulletin of the Buryat State University. Pedagogy. Philology. Philosophy], (1):32-35.

Gallas A. (2007) V derevnyakh, chtoby sokhranit' shkoly, usynovlyayut detey [Children are Adopted in Villages to Preserve Schools]. Baykal info [Baikal info]. Available at: http://baikalinfo.ru/number1/2007/07/005001.html (accessed 08.07.2019).

Gnedinskaya A. (2009) Sel'skie uchitelya spasli shkolu, i priyutskikh detey [Rural Teachers Save School and Orphans]. Moskovskiy komsomolets [Moscow Komsomol]. Available at: http://www. mk.ru/editions/daily/article/2009/08/31/343121-almamater.html (accessed 08.07.2019).

MOSP Horinskoe (2016) Naselenie [Population]. Available at: http://www.sphor.ru/onas/naselenie (accessed 8 July 2019).

Nefedova T. G. (2007) Mestnost', gde kadry reshayut vse [The Terrain Where Cardres Decide Everything]. Otechestvennye zapiski [Patriotic Notes], 3 (36): 214-229.

Postanovlenie pravitel'stva Respubliki Buryatiya (2006) Ob utverzhdenii respublikanskoj celevoj programmy 'Optimizaciya seti sel'skih obshcheobrazovatel'nyh uchrezhdenij v Respublike Buryatiya' na 2006-2008 gody [On the Approval of the Republican Target Programme 'Family and Children of the Republic of Buryatia for 2008-2014'] N 65 from 06.03.2006.

Postanovlenie pravitel'stva Respubliki Buryatiya (2007) Ob utverzhdenii respublikanskoj celevoj programmy 'Sem'ya i deti Respubliki Buryatiya na 2008-2014 gody' [On the Approval of the Republican Target Program 'Family and Children of the Republic of Buryatia for 20082014'] N 156 from 08.09.2007.

Respublikanskoe gosudarstvennoe uchrezhdenie 'Centr social'noj podderzhki naseleniya' Ministerstva social'noj zashchity naseleniya RB (2019) Social'nyj pasport naseleniya Respubliki Buryatiya na 1 iyunya 2019 goda [Social Profile of the Population of the Republic of Buryatia on 1 July 2019]. Available at: www.cspn-rb.ru/rehab/stat/passport/ (accessed 08 July 2019).

Serova E. V., Zvyagintsev D. V. (2006) Al'ternativnaya zanyatost' v sel'skoy mestnosti [Alternative employment in rural areas]. Mir Rossii [World of Russia], (4):3-34.

Serova E., Karpova N., Tikhonova T., Shik O., Mokshina P. (2006) Al'ternativnaya zanyatost' $v$ sel'skoy mestnosti Rossii [Alternative Employment in Rural Russia]. Moscow: Institut ekonomiki perekhodnogo perioda.

Shpakovskaya L., Kulmala M., CHernova ZH. (2019) Ideal'naya organizaciya zaboty o detyah, ostavshihsya bez popecheniya roditelej: reformy sistemy zashchity detej kak bor'ba za resursy i priznanie [The Ideal Organization of Care for Children Left without Parental Care: Russia's Child Welfare Reform as a Battle over Resources and Recognition]. Laboratorium, 11 (1):57-81.

Yin R. K. (2004) The Case-study Anthology. London: Sage.

Zakon Respubliki Buryatiya (2007) O vnesenii izmenenij v zakon Respubliki Buryatiya 'Ob obrazovanii' [On Amendments to the Law of the Republic of Buryatia 'On Education'] N51-IV from 27.12.2007.

Zakon Respubliki Buryatiya (2013) Ob obrazovanii v Respublike Buryatiya [On Education in the Republic of Buryatia] N 240-V from 13.12.2013. 